\title{
A MATEMÁTICA NA FORMAÇÃO DE NORMALISTAS MINEIROS(AS): 1890 A 1930
}

\author{
Silvia de Castro de Barros ${ }^{1}$ \\ Maria Cristina Araújo de Oliveira²
}

\section{Resumo}

Este artigo tem como objetivo apresentar uma descrição da matemática presente na formação de normalistas mineiros (as) entre 1890 e 1930, identificada a partir das normativas oficiais para a Escola Normal, confrontando-a com as propostas práticas para o ensino de geometria na escola primária veiculadas na Revista do Ensino de Minas Gerais. Tomou-se como referência, em um primeiro nível de compreensão, o conhecimento da legislação relativa à formação desses professores no período a ser pesquisado, focalizando a presença da geometria como disciplina. A utilização das Revistas como fonte para a pesquisa levou a um segundo nível de compreensão, por meio do qual se materializam e se explicitam os motivos pelos quais a geometria integra a formação dos professores primários. As principais fontes utilizadas para a investigação foram legislação educacional do estado de Minas Gerais e a Revista do Ensino.

Palavras-chave: Normalistas. Geometria. Revista do Ensino.

\section{MATHEMATICS IN THE TRAINING OF ELEMENTARY SCHOOL TEACHER IN THE BRAZILIAN STATE OF MINAS GERAIS: 1890 - 1930}

\begin{abstract}
This article aims to present a description of the mathematics offered in the training of Elementary School teacher in the Brazilian state of Minas Gerais between 1890 and 1930 . We start by a presentation from the official regulations for the Normal School, comparing it with the practical proposals for geometry teaching in primary school broadcast by the Revista do Ensino de Minas Gerais (Educational Journal of Minas Gerais). As a reference, in a first level of understanding, the legislation concerning the training of these teachers in the period searched was taken, focusing on the presence of geometry as a discipline. The use of journals as a source for research led to a second level of understanding, whereby is explained the reasons why the geometry is part of the training of elementary school teachers. The main sources used for research were educational legislation of the state of Minas Gerais and the Revista do Ensino.
\end{abstract}

Keywords: Elementary school teacher. Geometry. Magazine of Teaching.

\section{LA MATEMÁTICA EN LA FORMACIÓN DE NORMALISTAS MINEIROS(AS): 1890 A 1930}

\section{Resumen}

Este artículo tiene por objetivo presentar una descripción de la matemática presente en la formación de normalistas mineiros (as) entre 1890 y 1930, identificada desde las reglas oficiales para la Escuela Normal, en confronto con las propuestas prácticas para la enseñanza de geometría en la escuela

\footnotetext{
1 Mestranda do Programa de Pós-Graduação em Educação Matemática da UFJF. E-mail: <sbarros.mat@gmail.com>.

2 Professora Adjunta do Departamento de Matemática da Universidade Federal de Juiz de Fora - MG. Integra o corpo permanente do Programa de Pós - Graduação em Educação Matemática da UFJF. E-mail: <mcrisoliveira6@gmail.com>.
} 
primaria vehiculadas en la Revista do Ensino de Minas Gerais. Se ha tomado como referencia, en primer nivel de comprensión, el conocimiento de la legislación relativa con la formación de eses profesores en el período investigado, con foco en la presencia de la geometría como asignatura. La utilización de las Revistas como fuente para la investigación ha levado hasta un segundo nivel de comprensión, por medio del cual se materializan y se explicitan los motivos por los cuales la geometría integra la formación dos profesores primarios. Las principales fuentes utilizadas para la investigación fueron la legislación educacional del estado de Minas Gerais y la Revista do Ensino.

Palabras-clave: Normalistas. Geometría. Revista do Ensino.

\section{O INÍCIO DAS ESCOLAS DE FORMAÇÃO DE PROFESSORES PRIMÁRIOS NO BRASIL}

No século XVII, a formação de professores já era uma preocupação manifestada por Comenius, cientista, pedagogo, educador e escritor tcheco considerado o pai da didática moderna. Movido por essa preocupação, São João Batista de La Salle, que consagrou sua vida a ensinar crianças pobres instituiu, no ano de 1684, na cidade francesa de Reims, o primeiro estabelecimento destinado à formação de docentes com o nome de Seminário dos Mestres.

Mais tarde, no século XVIII, a França, país mais povoado, mais próspero e que se destacava no cenário mundial por ser reconhecido como o mais intelectualizado da Europa Ocidental, vivia o início da Revolução Francesa. Nessa época, inspirado pelos princípios da Revolução, Liberdade, Igualdade, Fraternidade, intensificam-se os debates sobre a instrução popular e a necessidade de criação de escolas encarregadas de preparar os professores, que seriam corresponsáveis pelas transformações exigidas pela sociedade. Foi pensando em implementar a mudança que se instalou em Paris, no ano de 1795, a primeira Escola Normal. Nessa época, já se fazia uma distinção entre Escola Normal Superior, destinada a formar os professores para atuarem no ensino secundário; e a Escola Normal Primária, que prepararia os mestres para atuarem na escola primária (SAVIANI, 2009).

No início do século XIX, mais precisamente no ano de 1802, após haver conquistado o norte da Itália, Napoleão Bonaparte instituiu a Escola Normal de Pisa, que se assemelhava à Escola Normal Superior de Paris e que formaria professores para o ensino secundário. No entanto, ao contrário da ideia inicial, essa instituição não se dedicou ao preparo didático-pedagógico, enveredando e transformando-se em escola de altos estudos. Ao longo do século XIX, outras Escolas Normais foram instituídas em países da Europa, como na Inglaterra e Alemanha, além dos Estados Unidos, nas Américas (SAVIANI, 2009). 
Silvia de Castro de Barros

No Brasil, após a Independência, em 1822, ascende o debate em torno da organização da instrução popular, e a referência oficial à formação dos professores aparece pela primeira vez em 15 de outubro de 1827, com a promulgação da Lei das Escolas de Primeiras Letras (RIO DE JANEIRO, 1827), que instituía o ensino pelo método mútuo. O artigo 60 dessa lei dispõe sobre o que os professores deveriam ensinar, em relação à matemática "as quatro operações da aritmética, prática de quebrados, decimais e proporções e as noções mais gerais de geometria prática" e, para atuarem como professores, os candidatos deveriam ser aprovados em exames das matérias de ensino, incluindo as anteriormente referidas (RIO DE JANEIRO, 1827, p. 72).

Em 1834 (BRASIL, 1834), com a promulgação do Ato Adicional, a instrução primária ficou sob a responsabilidade das províncias, que adotaram o modelo das Escolas Normais para a formação dos professores. Em 1835 é instituída, no país, a primeira Escola Normal na província do Rio de Janeiro, na cidade de Niterói, o que dá início a uma grande expansão destes estabelecimentos, fazendo surgir escolas em diversas outras províncias como, por exemplo, Minas Gerais e São Paulo. As Escolas Normais tinham uma formação específica, já que o objetivo era a preparação de professores para a escola primária e, por isso, constavam de seu currículo as mesmas matérias que seriam ensinadas nas escolas de primeiras letras. A importância maior era dada a esses conteúdos que os professores deveriam dominar, em detrimento do preparo didático-pedagógico.

Consideradas por alguns muito onerosas para a quantidade de alunos que formavam, as Escolas Normais passaram a ser fechadas em algumas províncias, a do Rio de Janeiro, por exemplo, e substituídas pelos professores adjuntos. Esses professores nada mais eram do que ajudantes dos regentes de classe, que iriam adquirir aperfeiçoamento nas matérias e práticas de ensino. No entanto, esse meio não foi adiante, e os cursos normais continuaram a ser instalados (SAVIANI, 2009).

Um fato determinante para a organização e funcionamento das Escolas Normais foi a reforma da instrução pública do estado de São Paulo, que teve início a partir da década de 1890. Segundo os propositores só a boa formação dos professores garantiria um ensino regenerador e eficaz, e essa formação caberia às Escolas Normais. A reforma possibilitou tanto um enriquecimento dos conteúdos curriculares, quanto maior atenção aos exercícios práticos de ensino. Posteriormente, tornou-se referência para outros estados do Brasil, havendo um 
intercâmbio entre educadores que iam estagiar em São Paulo, ou educadores paulistas que vinham participar da reestruturação do ensino em outros estados do país.

Entre as décadas de 30 e 40 surgiram os Institutos de Educação, instituições de ensino que se destacariam não só como local para ensino, também para pesquisa. A partir de 19 de março de 1932, através do Decreto n. 3810 (BIBLIOTECA VIRTUAL ANISIO TEIXEIRA, 1932), Anísio Teixeira transformou a Escola Normal do Distrito Federal, Rio de Janeiro, em Escola de Professores, tirando das Escolas Normais o peso de serem escolas de cultura geral e de cultura profissional. Daí em diante, passaram a fazer parte dos conteúdos curriculares do curso de formação de professores primários disciplinas como biologia educacional, sociologia educacional, psicologia educacional, história da educação, introdução ao ensino, entre outras que, acompanhando a influência do movimento da Escola Nova, vão imprimir mudanças na formação desses professores. Tal mudança se espalhará para o restante do Brasil.

\section{AS ESCOLAS NORMAIS E A FORMAÇÃO DE PROFESSORES EM MINAS GERAIS}

No século XIX, no estado de Minas Gerais, foram feitas duras críticas à instrução pública. Criticava-se a falta de escolas, de materiais, a ausência de professores devidamente habilitados para o exercício da profissão e a falta de escolas normais que preparassem adequadamente os professores para o trabalho pedagógico. Esta última crítica era considerada, pelos administradores da província, a principal causa do atraso em que se encontrava a instrução pública elementar mineira, sendo esse um dos motivos que conduziu à criação da Escola Normal de Ouro Preto, em 1835, mesmo ano em que foi instituída a Escola Normal do Distrito Federal. Contudo, a de Ouro Preto só foi instituída em 1840 (GOUVÊA; ROSA, 2000).

A importância adquirida pelas Escolas Normais na formação de professores, a partir de 1871, foi tão significativa no estado de Minas Gerais que desencadeou a implantação de outras tantas. Havia, nessa época, duas escolas, uma em Ouro Preto e outra em Campanha, e oito anos mais tarde, em 1879, as instituições já haviam se multiplicado, saltando para cinco o número de escolas, e chegando esse número a nove, em 1894 (GOUVÊA; ROSA, 2000).

Em 3 de agosto de 1892, com a Reforma Afonso Pena, Lei n. 41, é proposta uma nova organização da instrução pública mineira. Em 1893, com o Decreto n. 601, de 27 de 
fevereiro, chega a regulamentação para as Escolas Normais (GOUVÊA \& ROSA, 2000). A partir desta data, a mulher iniciaria sua participação na docência, e seria convocada a participar da instrução pública pois, acreditava-se que, por ter experiência no cuidado e educação dos filhos, seria mais indicada para exercer tal função. Essa convocação marcaria definitivamente tal atividade como uma função tipicamente feminina.

\section{A MATEMÁTICA NOS PROGRAMAS PARA AS ESCOLAS NORMAIS MINEIRAS - 1890 A 1930}

Em Minas Gerais, em 29 de agosto de 1898, as Escolas Normais foram regulamentadas com a promulgação do Decreto $\mathrm{n}^{\circ} 1.175$ (MINAS GERAIS, 1898), que determinava que o curso normal completo seria de 4 anos, e que constariam do programa de ensino as seguintes matérias de Matemática: aritmética e desenho geométrico no 1aa ano; aritmética, álgebra e desenho topográfico no 2 ㅇaㅇ álgebra, geometria plana e desenho de ornato no 3 o ano e geometria no espaço e desenho de figura e de paisagem no 4 ano. No estudo da álgebra, a recomendação era de que se habilitassem os alunos para o estudo da geometria, resolvendo as fórmulas geométricas das linhas, áreas e volumes. Em 1901, o Decreto no 1479 (MINAS GERAIS, 1901), em seu artigo 11, definia relativamente aos saberes matemáticos, a aritmética elementar, a geometria plana e o desenho linear como disciplinas do curso normal. Percebe-se que, concernente à normatização do século XIX, o novo Decreto simplifica os saberes matemáticos propostos aos normalistas mineiros, não fazendo menção à álgebra, reduzindo a geometria exclusivamente ao plano e o desenho, unicamente o linear.

Sob a influência da reforma paulista, que implantou o modelo dos grupos escolares, em 28 de setembro de 1906, a Reforma João Pinheiro, através da Lei n. 439 (MINAS GERAIS, 1906a), reformulava o ensino primário, normal e superior do Estado de Minas Gerais. Posteriormente, o Decreto $n^{\circ}$ 1.960, de 16 de dezembro de 1906 (MINAS GERAIS, 1906 b), criava a Escola Normal da Capital de Minas Gerais, que atenderia exclusivamente ao público feminino, e cujo curso teria a duração de três anos. Nele, a Matemática seria inserida da seguinte forma: no $1^{\circ}$ ano, aritmética e desenho; no $2^{\circ}$ ano, geometria e desenho e no 3 ano, aritmética comercial e desenho. Acompanhando a normatização de 1901, não há, nesta reforma, referência à álgebra como disciplina do curso normal, o desenho perde suas especificações e a geometria não fica explícita em qual domínio, se plano ou espacial. 
Em 1910, uma nova reorganização das escolas normais, em Minas Gerais, foi regulamentada pelo Decreto no 2.836, de 31 de maio (MINAS GERAIS, 1910). O curso normal passaria, a partir de então, a ter a duração de quatro anos e seria distribuído em quatorze cadeiras. Dentre elas constavam a aritmética, geometria e desenho linear, e desenho, no que se refere aos conteúdos de Matemática. Segundo esta normativa as matérias de ensino seriam distribuídas do seguinte modo: 1으 ano - aritmética e desenho; 2ำ ano - aritmética, geometria e desenho linear; 3ำ ano - geometria e desenho linear, desenho e caligrafia; 4ํano - aritmética comercial. Segundo o Artigo 8 do regulamento, o desenho compreenderia a reprodução de objetos e de formas simples da natureza; porém, não havia detalhamento sobre o ensino de aritmética e geometria. Os métodos intuitivos e práticos seriam incentivados em detrimento da memorização, e não haveria separação entre geometria plana e geometria espacial, ou maiores referências ao desenho geométrico.

Na década de 1920, no governo Antônio Carlos Ribeiro de Andrada, a fundação da Escola de Aperfeiçoamento para professores primários e a possibilidade da experimentação de novos métodos de ensino foram iniciativas intimamente relacionadas com a ida de professoras mineiras aos Estados Unidos para realizarem estudos e para se capacitarem. Situada em Belo Horizonte, a Escola tinha como objetivo permitir às professoras primárias mineiras que frequentassem curso sintonizado com os princípios da Escola Nova, para que pudessem seguir as novas diretrizes pedagógicas então em voga. Nessa época, entre 1928 e 1930, mais de três mil unidades de ensino primário e vinte e uma Escolas Normais foram criadas, caracterizando o momento de expansão do sistema público de ensino mineiro. Tal expansão foi responsável pela profissionalização do professor primário mineiro e consolidou a Escola Normal como lugar específico para sua formação e especialização (GOUVÊA; ROSA, 2000).

A Escola de Aperfeiçoamento de Minas Gerais nasceu como um centro de estudos e pesquisas, que seria responsável pela renovação do ensino mineiro. No início, esteve sob a influência americana quanto às ideias da Escola Nova, e foi com base nessa influência que cinco professoras primárias realizaram estágios no Teacher's College, na Universidade de Columbia, Nova York. No que tange às propostas mais ligadas à psicologia, houve, também, a influência europeia (REIS, 2014). No corpo docente da Escola de Aperfeiçoamento destacouse a professora mineira Alda Lodi, nascida em Belo Horizonte, em 17 de dezembro de 1898, 
que atuou na primeira classe mista da Escola Normal Modelo. Alda Lodi foi responsável pela formação de várias gerações de professores para os anos iniciais e professores de Matemática em Minas Gerais, e atuou nesta Escola entre 1927 e 1950, lecionando Metodologia da Aritmética (REIS, 2014).

Alda Lodi foi uma das fundadoras da Escola de Aperfeiçoamento e uma das cinco professoras escolhidas, pelo então Secretário dos Negócios do Interior de Minas Gerais, Francisco Campos, para aprimorar sua formação docente no Instituto Internacional do Teacher's College, em 1927. Esse Instituto foi um centro mundialmente famoso por divulgar, na época, o método da Escola Ativa. Nessa época acontecia, em Minas Gerais, a chamada Reforma Francisco Campos, que se caracterizou por uma grande reforma nos ensinos primário e normal. A professora Alda Lodi permaneceu por lá durante dois anos, só retornando ao país em agosto de 1929 (REIS, 2014).

Em 1930, pelo Decreto n. 9.450 de 18 de fevereiro (MINAS GERAIS, 1930), Francisco Campos aprovou a divisão do ensino normal em dois graus, cabendo ao Estado oferecer o segundo grau por se tratar de um curso mais longo e mais completo. Às escolas particulares sob fiscalização do Estado, ficou o encargo de oferecerem o curso normal de primeiro grau. As escolas normais de segundo grau tiveram seu ensino dividido em três cursos: o de adaptação, cuja duração era de dois anos; o preparatório, com duração de três anos; e finalmente, o de aplicação, com duração de dois anos. No curso de adaptação lecionava-se aritmética, desenho, educação física, trabalhos manuais e modelagem, entre outras matérias. No preparatório, no que se refere à Matemática, constavam matérias como aritmética, geometria e desenho linear, desenho figurado, trabalhos manuais e modelagem, entre outras. Aritmética, desenho, trabalhos manuais e modelagem constavam do primeiro ano; aritmética, geometria, desenho, trabalhos manuais e modelagem no segundo ano e, no terceiro ano, desenho.

O curso de aplicação tinha a duração de dois anos, e seu objetivo era a formação profissional dos aspirantes ao magistério primário. Desse curso constavam cadeiras como: psicologia educacional; biologia e higiene; metodologia; história da civilização, particularmente história dos métodos e processos da educação; prática profissional. 
No curso normal de primeiro grau, lecionava-se aritmética no primeiro ano; aritmética e noções de geometria, desenho, trabalhos manuais e modelagem no segundo ano; no terceiro ano não havia matérias relacionadas à Matemática.

A legislação em Minas Gerais, no que tange às Escolas Normais, entre 1890 e 1930, contemplava o ensino de Matemática particularmente nos ramos: aritmética, desenho e geometria. Pouco a pouco passou-se a pregar que o ensino normal deveria ter caráter prático e profissional, de tal forma que pudesse desenvolver, no futuro professor, suas qualidades intelectuais e morais, privilegiando, sempre que possível os processos intuitivos.

\section{AS NORMATIVAS OFICIAIS RUMO À SALA DE AULA: A GEOMETRIA NA REVISTA DE ENSINO}

O estudo dos periódicos educacionais fornece farto material sobre as práticas escolares do ensino de disciplinas, criando, assim, "a possibilidade de se estabelecer um dos elos da história das práticas e das disciplinas escolares" (CATANI; VILHENA, 1994, p. 178).

O exame de alguns exemplares da Revista do Ensino, publicada entre as décadas de 1920 e 1930, permite compreender melhor o papel da geometria proposta às normalistas. A Revista do Ensino foi uma publicação oficial da Inspetoria Geral da Instrução do Estado de Minas Gerais, criada em 1892, mas desativada após a publicação de apenas três números. Foi relançada em março de 1925, sendo interrompida entre os anos de 1940-1946, devido à Segunda Guerra Mundial, voltando a circular até 1971 (BICCAS, 2008). Segundo Biccas (2008, p. 197), a Revista do Ensino pode ser considerada "um dispositivo de normatização pedagógica e de ampliação da cultura educacional dos professores". No início da década de 1930, a Revista foi um importante veículo de divulgação e discussão sobre as propostas e a implementação de novas práticas, a partir da influência do movimento escolanovista. Mesmo sob a influência das propostas da Escola Nova, que foram fortemente defendidas e veiculadas nessa publicação mineira, o método intuitivo e as lições de coisas mantiveram-se como modelos para o ensino ativo.

Dentre tantas sugestões apresentadas na Revista do Ensino, encontramos o que hoje chamamos de Caderno de Planejamento. Naquela época recebia o nome de Caderno de Preparação de Lições, no entanto, a utilidade que tinha era a mesma dos dias atuais, ou seja, ele era "um summario das matérias a expôr com a indicação não só do que se ha de dizer, mas 
dos methodos e expedientes pedagogicos para mais facil transmissão" (REVISTA DO ENSINO, Ano III, n 26, MG, 1928, p. 4). Ainda, segundo a Revista, não existia "regras especiaes nem limites no fazê-lo" (REVISTA DO ENSINO, Ano III, no 26, MG, 1928, p. 18), mas deveria ser feita a preparação das lições com muito cuidado pelos professores, de tal forma que estes pudessem provar que as haviam preparado. Entretanto, o que se chamava preparar uma aula àquela época? De acordo com a Revista,

Preparar é tomar o programma; ver o ponto; estudar o regulamento e as instruções especiaes à matéria; determinar os limites da matéria, cortando o que achar de mais; dosar, por assim dizer, o ponto; fazer exercícios referentes ao ponto, para melhor explicá- lo; dar um resumo final; escolher exemplos; estudar previamente os problemas a propor; meditar sobre os modos de expor a materia; ponderar os meios disciplinares de que hade lançar mão, para alcançar o seu objetivo (REVISTA DO ENSINO, Ano III, no 26, MG, 1928, p. 19).

A preparação das aulas, entre as obrigações e os deveres dos professores, era parametrizada pelo Decreto n. 7970 A (MINAS GERAIS, 1927), de 15 de novembro de 1927, que aprovava o Regulamento do Ensino Primário em Minas Gerais em seus artigos 316 e 437 (REVISTA DO ENSINO, Ano III, no 26, MG, 1928).

Pode-se afirmar que esse Caderno de Preparação de Lições era capaz de revelar o quão competente, interessado e dedicado era o professor, pois "Nada melhor para revelar a cultura, o esforço, a exactidão no cumprimento do dever. Quem prepara diligentemente as lições pôde, por certo, dar boas aulas, porque o trabalho de preparar é para o indolente muito mais fastidioso do que matar o tempo numa aula" (REVISTA DO ENSINO, Ano III, no 26, MG, 1928, p. 19).

Entre tantas aulas sugeridas em uma das Revistas de Ensino, tomamos como exemplo uma aula de Geometria para o 4으 ano primário, preparada e registrada nesse Caderno de Preparação de Lições (REVISTA DO ENSINO, Ano III, no 26, MG, 1928, p. 24). Analisando essa aula, notamos que o conteúdo a ser ensinado privilegiava as figuras geométricas, particularmente os quadriláteros, explorando suas definições. O professor apresentava à classe diversos exemplos de quadriláteros, tomava-os dois a dois e começava a interagir com seus alunos de forma que os mesmos definissem cada exemplo. Durante a aula, várias perguntas eram feitas aos alunos, de forma que eles próprios concluíssem as definições que o professor desejava. Para tanto, figuras em madeira ou arame eram utilizadas pelo 
professor na estimulação de dois órgãos sensoriais: a visão e o tato. Essa metodologia muito peculiar era própria do Método Intuitivo, e chegou ao Brasil através do manual do americano Norman Allison Calkins, cuja tradução recebeu o título de Primeiras Lições de Coisas (Revista HISTEDBR, [s.d.]).

Em outra aula, desta vez para o 4 을 ano primário (REVISTA DE ENSINO, ano IV, no 35,1929, p.69), agora utilizando frutas das mais diversas variedades, o professor aproveita-se da observação para uma aula de geometria, explorando as formas geométricas de cada uma das frutas: laranja, figo, banana, abacaxi e outras. A proposta era que o aluno identificasse a forma geométrica espacial mais próxima ao formato da fruta, por exemplo, uma laranja se assemelha a uma esfera. Em outra aula, para o $3^{\circ}$ ano, contida na Revista do Ensino (ano IV, no 38,1929$)$, a figura apresentada é um quadrado, e a professora, através de duas linhas auxiliares perpendiculares, ensina o processo de construção da figura.

Observa-se, em ambos os casos, uma forma de ensinar própria do Método Intuitivo, que o fazia através da "valorização do ensino pelo domínio das coisas: a educação dos sentidos pela observação direta dos objetos e das coisas da natureza" (RESENDE; SOUZA, 2005, p. 2).

\section{CONSIDERAÇÕES FINAIS}

Fazendo uma análise das aulas propostas nas Revistas de Ensino anteriormente mencionadas e confrontando-as com as ideias propostas pelo Método Intuitivo e pelas Lições de Coisas, pode-se ver, nessas aulas, a forma de apropriação do Método para o ensino de geometria. Nas aulas de Geometria, estando com os objetos ao alcance dos olhos e das mãos, recomendava-se que o estudo das propriedades de cada uma das figuras se desse pela observação das formas e pelo roteiro de questões formuladas pelo professor e respondidas pelos alunos.

O ensino com base no Método Intuitivo deveria privilegiar o concreto e a observação como elementos constitutivos do saber escolar, o livro seria apenas um auxiliar. Segundo Ferdinand Buisson (1897),

\footnotetext{
"as coisas antes das palavras, a educação pelas coisas e não a educação pelas palavras". Despertar e aguçar o sentido da observação, em todas as idades,
} 
em todos os graus de ensino, colocar a criança na presença das coisas, fazêlas ver, tocar, distinguir, medir, comparar, nomear, enfim, conhecê-las, este é o objetivo das lições de coisas no ensino primário e nos jardins de infância, cuja aplicação pode ser feita através de dois sistemas: como um exercício à parte ou uma lição distinta, tendo uma hora reservada para aplicação dentro do programa de ensino ou aplicada em todas as disciplinas escolares, inserida em todo programa de ensino (BUISSON, 1897, apud Revista HISTEDBR, 2015, [s.p.], grifos do autor).

Preconizado pelo método das Lições de Coisas, a utilização dos cinco sentidos seria de extrema importância para o aprendizado. Segundo Gomes (2011, p. 61),

[...] o cultivo da visão, da audição, do olfato, do paladar e do tato da criança deve começar em casa, antes da idade escolar, e, por isso, o autor empenhase em sugerir exercícios detalhados para educar os cinco sentidos domesticamente. Noções matemáticas estão envolvidas nessas atividades: a vista deve ser cultivada para a distinção das formas, da largura, do comprimento e do volume dos objetos; o ouvido pode ser exercitado para a localização da própria criança e de objetos em um ambiente; o tato precisa ser treinado para distinguir tamanhos e formas.

Assim, a geometria proposta às normalistas deveria ser capaz de possibilitar, sobretudo, a exploração das formas, das propriedades das figuras planas e espaciais. No período estudado, o método intuitivo e as lições de coisas foram o paradigma de ensino para o primário e a formação das normalistas, e tomava em conta tal orientação, particularmente quando eram analisadas as normativas oficiais. Os exemplos das aulas apresentados na Revista do Ensino concretizavam os princípios intuitivos para o ensino da geometria.

\section{REFERÊNCIAS}

BIBLIOTECA VIRTUAL ANISIO TEIXEIRA. Reorganização do ensino normal e sua transposição para o plano universitário: creação do Instituto de Educação do Rio de Janeiro. Exposição de motivos Director Geral de Instrucção, acompanhando o Decreto que tomou o no 3.810, de 19 de Março de 1932. Disponível em: < http://www.bvanisioteixeira.ufba.br/artigos/reorganizacao.html>. Acesso em: 12 out. 2014 BICCAS, M. S. O impresso como estratégia de formação: Revista do Ensino de Minas Gerais (1925-1940). Belo Horizonte: Argvmentvm, 2008. 216 p.

BRASIL. LEI № 16, DE 12 DE AGOSTO DE 1834. Disponível em: $<$ http://www2.camara.leg.br/legin/fed/leimp/1824-1899/lei-16-12-agosto-1834-532609publicacaooriginal-14881-pl.html>. Acesso em: 05 mai. 2014 
Silvia de Castro de Barros

CATANI, D. B.; VILHENA, C. P. S. A Imprensa Periódica Educacional e as fontes para a História da Cultura Escolar Brasileira. Revista do IEB (Instituto de Estudos Brasileiros), São Paulo, v. 37, p. 177-183, 1994.

GOMES, M. L. M. Lições de coisas: apontamentos acerca da geometria no manual de Norman Allison Calkins (Brasil, final do século XIX e início do XX) Revista Brasileira de História da Educação- v. 11, n. 2 [26]- 2011

GOUVÊA, M. C. S. de; ROSA, W. M. A Escola Normal em Minas Gerais- documento comemorativo dos 70 anos da SEE- MG- Lições de Minas -2000 - Centro de Referência Virtual do Professor. Disponível em: <http://crv.educacao.mg.gov.br >- Acesso em: 15 abr. 2014.

MINAS GERAIS. Secretaria de Educação. Estado de Minas Gerais. Decreto no 1.175 de 29 de agosto de 1898. Regulamenta as escolas normais com os planos de ensino para as mesmas. Disponível em: < https://repositorio.ufsc.br/handle/123456789/122515>. Acesso em 08 jan. $\underline{2015}$.

MINAS GERAIS. Secretaria de Educação. Estado de Minas Gerais. Decreto $n^{\circ} 1479$, de 21 de outubro de 1901- Põe em execução a lei n. 318 de 16 de setembro de 1901, da parte referente a Secretaria do Interior. No Art. 11 define que a Aritmética Elementar, a Geometria Plana e o Desenho Linear constarão na grade do curso normal. Disponível em: <https://repositorio.ufsc.br/handle/123456789/115910>. Acesso em: 8 jan. 2015.

MINAS GERAIS. Secretaria de Educação. Estado de Minas Gerais. Lei no 439, de 28 setembro de 1906a - Autoriza o governo a reformar o ensino primário, normal e superior do estado e dá outras providências. Disponível em:

<http://www.almg.gov.br/consulte/legislacao/completa/completa.html?tipo=Lei\&num=439 \&comp $=\& a n o=1906>$. Acesso em: 19 fev. 2015.

MINAS GERAIS. Secretaria de Educação. Estado de Minas Gerais. Decreto n 1.960 de 16 de dezembro de 1906b. Regulamento da instrução pública primária de Minas Gerais.

Disponível em: <https://repositorio.ufsc.br/handle/123456789/121823>. Acesso em: 8 jan. 2015.

MINAS GERAIS. Secretaria de Educação. Estado de Minas Gerais. Decreto no 2.836 de 31 de maio de 1910. MG. Aprova o regulamento que reorganiza as escolas normais do estado. Disponível em: <https://repositorio.ufsc.br/xmlui/handle/123456789/122290>. Acesso em: 08 jan. 2015.

MINAS GERAIS. Secretaria de Educação. Estado de Minas Gerais. Decreto n 7970-A, de 15 de Outubro de 1927, MG. Aprova o regulamento do ensino primário do estado de Minas Gerais. Disponível em: <https://repositorio.ufsc.br/handle/123456789/105945>. Acesso em: 08 jan. 2015. 
MINAS GERAIS. Secretaria de Educação. Estado de Minas Gerais. Decreto n. 9.450 de 18 de fevereiro de 1930, MG. Regulamenta o ensino normal. Disponível em:

<http://repositorio.ufsc.br/handle/123456789/125158>. Acesso em: 08 de ago. 2014. REIS, D. A. de F. HISTÓRIA da formação de professores de Matemática do ensino primário em Minas Gerais: estudos a partir do acervo de Alda Lodi (1927 a 1950). Tese (Doutorado em Educação), Universidade Federal de Minas Gerais, Belo Horizonte, 2014.

RESENDE, F. M.; SOUZA, R. de C. de. O Método Intuitivo e a Escola Nova: discussões educacionais em fins do século XIX e início do século XX. UFMG- 2005. Disponível em $<$ http://www.fae.ufmg.br/portalmineiro/conteudo/externos/3cpehemg/congresso/textos p df- $>$. Acesso em: 05 jan. 2015.

REVISTA DO ENSINO, Ano III, no 26, MG, 1928. ., Ano IV, no 38, MG, 1929.

REVISTA HISTEDBR- Navegando na história da educação brasileira- Lições de CoisasFaculdade de Educação- UNICAMP. Disponível em <http://www.histedbr.fe.unicamp.br/navegando/glossario/verb c licoes das coisas.htm-> Acesso em: 05/01/2015

RIO DE JANEIRO. Lei de 15 de outubro de 1827- Criação de Escolas de Primeiras Letras em todas as cidades, villas e logares mais populosos do Imperio. Disponível em: <https://repositorio.ufsc.br/handle/123456789/99972>. Acesso em: 8 jan. 2015.

. Lei $n$ ㅇ 16, de 12 de Agosto de 1834- Faz algumas alterações e adições à Constituição Política do Império, nos termos da Lei de 12 de outubro de 1832. Disponível em: <http://www2.camara.leg.br/legin/fed/lei/1824-1899/lei-16-12-agosto-1834-532609publicacaooriginal-14881-pl.html> . Acesso em: 19 fev. 2015

SAVIANI, D. Formação de professores: aspectos históricos e teóricos do problema no contexto brasileiro. Revista Brasileira da Educação, v.14. jan. /abr. 2009.

\section{RECEBIDO EM 12 DE JUNHO DE 2015.}

APROVADO EM 27 DE OUTUBRO DE 2016. 